\title{
National Health Insurance in South Africa: Relevance of a national priority-setting agency
}

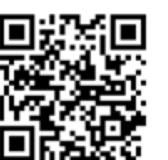

Universal health coverage (UHC) has become a comprehensive global aspiration, and many countries have now committed to processes to deliver it. ${ }^{[1]}$ In pursuit of realising this objective, it will be crucial to find ways to contend with the tensions between supply of and demand for quality services, as well as effective interventions in health systems with finite budgets. In doing so, trade-offs are inevitable and the need to set priorities becomes crucial.

The World Health Assembly Resolution (67.23) of 2014, to which South Africa (SA) is a signatory, is entitled 'Health Intervention and Technology Assessment in Support of Universal Health Coverage. ${ }^{[2]}$ It identifies the 'critical role of independent health intervention and technology assessment' in generating evidence to inform prioritisation, selection, introduction, distribution and management of interventions for health promotion, disease prevention, diagnosis and treatment, rehabilitation and palliation. ${ }^{[2]}$

SA has pledged to deliver UHC over two decades through the mechanism of National Health Insurance (NHI). ${ }^{[3]}$ Its governance and the mechanism of its financing are still under consideration, but NHI pilot districts have been identified and work in these has begun. One aspect of the NHI policy that has received little attention is ensuring that everyone has access to a 'defined comprehensive package of healthcare services. ${ }^{[3]}$ There are few, if any, countries that can provide complete coverage of quality services, whether preventive or curative, to every citizen, so addressing the comprehensiveness of a package in $\mathrm{SA}$ is a pressing issue.

The Lancet Commission on Investing in Health has recommended 'progressive universalism' as a means to achieving UHC. ${ }^{[4]}$ Some countries have begun the process with a minimum package that is increasing incrementally over time, ${ }^{[5]}$ while others have defined a comprehensive healthcare service package that is available for a subset of the public at first and subsequently expanded to other subpopulations. ${ }^{[6]}$ While currently implicit in SA, a more explicit transparent and evidence-informed approach is needed with regard to which services and technologies might realistically be covered or not. Without this understanding we will not achieve the best value for healthcare spending, nor is NHI likely to successfully address our severely unequal society, with life expectancies and health-related qualities of life much below what they could be.

Policy-makers faced with similar challenges around the world are increasingly adopting instruments and mechanisms that overtly define the technologies and health services covered and reimbursed by public or private entities. ${ }^{[7]}$ These include medicines lists, health benefit plans and health technology assessment (HTA). ${ }^{[7,8]}$ HTA has been implemented formally by several high-income countries where UHC exists, and is increasingly being adopted in low- and middle-income settings. ${ }^{[7]}$

There are several criteria to use in making decisions about what elements that link to equity to include in the package, and how to include them - cost-effectiveness thresholds, feasibility of implementation and burden of disease, among others. Techniques for combining these disparate elements can be challenging, some of them related to uncertainties regarding data and evidence. In this respect, learning from other settings is important, while ensuring that due consideration is given to the country-specific historical, political and social context. ${ }^{[9,10]}$

In addition, it is widely recognised that wide and transparent stakeholder engagement on issues of decision-making and prioritisation is key to the success of these processes, with authorities setting out guidelines aimed at encouraging participation from the public, patient groups, healthcare providers and the medicines and devices industry. ${ }^{[1,12]}$

\section{Institutionalising decision-making and priority-setting}

The SA National Health Act of 2003 places the responsibility for equitable prioritisation of health services provided by the state with the Minister of Health and the Director-General, who are tasked to 'identify national health goals and priorities and monitor the progress of their implementation. ${ }^{[13]}$ The Minister's prioritisation process is to be informed by the National Health Council, which is also supposed to advise the Minister on 'development procurement and use of health technology. ${ }^{[13]}$ At the subnational level, provincial health councils are to advise provincial executive committees on the same issues. ${ }^{[13]}$

The trend internationally seems to be one of increased institutionalisation of HTA and decision-making bodies. ${ }^{[14]}$ HTA agencies have developed in several middle-income countries in South-East Asia, Latin America and Central Europe. They take various forms, but have generally been empowered to generate and apply evidence in a consultative process and either to advise on or make resource allocation decisions for the health systems in which they operate. The successes of institutions such as the Health Intervention and Technology Assessment Program (HITAP) in Thailand ${ }^{[15]}$ and development of their counterparts in other South-East Asian countries in support of UHC have highlighted several models to consider for others embarking on this journey. ${ }^{[16-18]}$ In many cases these agencies are directly affiliated to, but at arms' length from, their ministries of health. This has the benefit of distancing ministers from potentially unpopular decisions while also reinforcing the professional independence of the agency.

\section{Taking up the cause}

In March 2015, the first meeting of the International Decision Support Initiative (iDSI) in Africa was held at the School of Public Health at the University of the Witwatersrand, Johannesburg, SA. The iDSI (http://www.idsihealth.org/), established in 2013, is a global partnership of leading government institutes, universities and think tanks, including NICE International (the National Institute for Health and Care Excellence) in England and Wales, HITAP, PRICELESS SA (Priority Cost-Effective Lessons for System Strengthening) (www. pricelesssa.ac.za), the Center for Global Development in Washington, DC, and the universities of York in England and Glasgow in Scotland, to support policy makers in priority-setting for UHC. The mission of the collaboration is to guide decision makers to effective and efficient healthcare resource allocation strategies for improving people's health.

The iDSI supports low- and middle-income governments in considering how to formulate resource allocation decisions for healthcare. Specifically, the initiative aims to share experiences, showcase lessons learned and identify practical ways to scale up technical support for systematic, fair and evidence-informed prioritysetting processes. Strengthening priority-setting institutions will enhance access to effective health interventions, and the quality and efficiency of healthcare delivery. Most importantly, it helps elevate the value of priority-setting as essential for attaining and sustaining UHC.

The first meeting brought together some 70 stakeholders to begin to identify ways of scaling up practical support for more systematic, fair and evidence-informed healthcare priority-setting 
for all South Africans. Delegates included senior government officials and policy makers from the Department of Health and the Treasury, development partners, statutory bodies, the private sector (medical schemes, pharmaceuticals and devices), researchers and leaders in priority-setting from the UK, Thailand and Zambia.

The focus of discussions was to learn from the experience of prioritysetting in SA and abroad and to identify the current range and depth of available technical capacity to support priority-setting and to strengthen such capacity. A health technology was defined in the broadest sense as an intervention that may be used to promote health, to prevent, diagnose or treat acute or chronic disease, or for rehabilitation. The term HTA is often confined to pharmaceuticals and devices, but can also include clinical guidelines and organisational systems used in healthcare. ${ }^{[19]}$

\section{Current priority-setting in SA}

While not always transparent, some public and private sector groups are already using HTA and economic evaluation in SA for prioritysetting and decision-making processes.

Several research units based at academic and self-funded institutions are already conducting research and providing training in economic evaluation and pharmacoeconomic assessment. The Directorate of Affordable Medicines in the National Department of Health recognises the importance of economic evaluation and has included it as one of the criteria for their processes for essential medicines selection. The recently published tertiary and quaternary essential medicines list suggests that these specialised medicines have been scrutinised, but the rationale for positive or negative recommendations is not explicit. ${ }^{[20]}$

The Council for Medical Schemes, which regulates the private medical schemes, is endeavouring to incorporate aspects of HTA in its decision-making for benefit design and protocols for reimbursement. ${ }^{[21]}$

Much of the economic evaluation research work in SA has focused on the curative aspects of the HIV/AIDS and tuberculosis epidemics, but it is increasingly expanding to four other priority areas: maternal and child health, ${ }^{[22]}$ reproductive health, ${ }^{[23]}$ injury, and non-communicable disease. ${ }^{[24]}$

It is not clear to what extent any of these analyses are utilised in resource allocation decisions. Without institutionalising and formalising processes to inform such decisions, the current approach can perversely impact on capacity, resources and government ability to spend its healthcare and prevention budget. Strong stewardship could assist in co-ordinating and guiding activities to address the policy demand for good-quality evidence for decision-making.

Supported by the iDSI, the PRICELESS SA programme at the Wits School of Public Health is investigating existing functions, processes and capacity available for priority-setting mechanisms and health technology assessment in SA to determine ways to improve the adoption and use of critical appraisal and analytics, and the evidence they generate, for policy-making.

\section{Conclusion}

SA could achieve better value for money in its healthcare services. Plans to reform the system have implications for affordability, as salaries increase and new technologies and medications come on line. Consideration of health system constraints, cost-effectiveness of programmes and preventive interventions and the full assessment of new and existing technologies through a democratic process should form the basis of a priority-setting function to advise the Department of Health on the incorporation of these into its future UHC plans. With evidence mounting that implementation of UHC can be a costly exercise, informed priority-setting will be key to ensuring that public financing for health is used effectively, efficiently and equitably.

\section{Karen J Hofman, Shelley McGee}

PRICELESS SA and Medical Research Council/University of the Witwatersrand Rural Public Health and Health Transitions Research Unit (Agincourt), School of Public Health, Faculty of Health Sciences, University of the Witwatersrand, Johannesburg, South Africa

\section{Kalipso Chalkidou}

National Institute for Health and Care Excellence, NICE International, Brighton and Hove, UK

\section{Sripen Tantivess}

Health Intervention and Technology Assessment Programme, Ministry of Public Health, Thailand

\section{Anthony J Culyer}

Centre for Health Economics, University of York, UK, and Institute for Health Policy Management and Evaluation, University of Toronto, Canada

\section{Corresponding author: KJ Hofman (karen.hofman@wits.ac.za)}

1. World Bank Group. Universal Health Coverage Overview. 2015. http://www.worldbank.org/en/topic/ universalhealthcoverage/overview (updated March 2015, accessed 2 June 2015).

2. World Health Assembly Resolution 67.23: Health Intervention and Technology Assessment in Suppor of Universal Health Coverage. Geneva: World Health Organisation, 2014. http://apps.who.int/gb/ ebwha/pdf_files/WHA67/A67_R23-en.pdf (accessed 7 August 2015).

3. National Health Insurance Policy Paper. Pretoria: National Department of Health, 2011.

4. Jamison DT, Summers LH, Alleyne G, et al. Global health 2035: A world converging within a generation. Lancet 2013;382(9908):1898-955. [http://dx.doi.org/10.1016/S0140-6736(13)62105-4]

5. Damrongplasit K, Melnick G. Funding, coverage, and access under Thailand's universal health Damrongplasit K, Melnick G. Funding, coverage, and access under Thailand's universal health
insurance program: An update after ten years. Appl Health Econ Health Policy 2015;13(2):157-166. insurance program: An update after ten years.
[http://dx.doi.org/10.1007/s40258-014-0148-z]

6. Ha BTT, Frizen S, Thi LM, Duong DTT, Duc DM. Policy processes underpinning universal health insurance in Vietnam. Glob Health Action 2014;7:24928. [http://dx.doi.org/10.3402/gha.v7.24928]

7. Glassman A, Chalkidou K. Priority-setting in Health: Building Institutions for Smarter Public Spending. Washington, DC: Center for Global Development's Priority-setting Institutions for Global Health Working Group, 2012

8. Giedion U, Bitran R, Tristao I, eds. Health Benefit Plans in Latin America: A Regional Comparison. Washington, DC: Inter-American Development Bank Social Protection and Health Division, 2014.

9. Pichon-Riviere A, Augustovski F, Garcia Marti S, Sullivan SD, Drummond M. Transferability of health technology assessment reports in Latin America: An exploratory survey of researchers and decision makers. Int J Technol Assess Health Care 2012;28(2):180-186. [http://dx.doi.org/10.1017//0266462312000074]

10. Goeree R, He J, O'Reilly D, et al. Transferability of health technology assessments and economic evaluations: A systematic review of approaches for assessment and application. Clinicoecon Outcomes Res 2011;3:89-104. [http://dx.doi.org/10.2147/CEOR.S14404]

11. Health Information and Quality Authority. Guidelines for Stakeholder Engagement in Health Technology Assessment in Ireland. Dublin: Health Information and Quality Authority, 2014.

12. National Institute for Health and Clinical Excellence. The Guidelines Manual. November 2012. http:// www.nice.org.uk/article/pmg6/chapter/11-the-consultation-process-and-dealing-with-stakeholder-
comments (accessed 10 July 2015)

13. South African National Department of Health. National Health Act 61 of 2003. 2003. http://www.gov. za/sites/www.gov.za/files/a61-03.pdf (accessed 7 August 2015)

4. Hailey D. Development of the International Network of Agencies for Health Technology Assessment. In J Technol Assess Health Care 2009;25(Suppl 1:)24-27. [http://dx.doi.org/10.1017/S0266462309090370]

15. Teerawattananon Y, Tritasavit N, Suchonwanich N, Kingkaew P. The use of economic evaluation for guiding the pharmaceutical reimbursement list in Thailand. Z Evid Fortbild Qual Gesundhwes 2014;108(7):397-404. [http://dx.doi.org/10.1016/j.zefq.2014.06.017]

16. Chiu W-T, Pwu R-F, Gau C-S. Affordable health technology assessment in Taiwan: A model for middle-income countries. J Formos Med Assoc 2015;114(6):481-483. [http://dx.doi.org/10.1016/j. jfma.2015.01.016]

17. Teerawattananon Y, Tantivess S, Yothasamut J, Kingkaew P, Chaisiri K. Historical development of health technology assessment in Thailand. Int J Technol Assess Health Care 2009;25(Suppl. 1):1-12 [http://dx.doi.org/ 10.1017/S0266462309090709]

18. Augustovski F, Alcaraz A, Caporale J, García Martí S, Pichon Riviere A. Institutionalizing health . Augustovski F, Alcaraz A, Caporale J, Garcia Marti S, Pichon Riviere A. Institutionalizing health
technology assessment for priority setting and health policy in Latin America: From regional endeavors to national experiences. Expert Rev Pharmacoecon Outcomes Res 2014;15(1):9-12. [http:/ dx.doi.org/10.1586/14737167.2014.963560]

19. Facey K. International HTA Glossary: English Version: International Network of Agencies for Health Technology Assessment (INAHTA). 2006. http://htaglossary.net/HomePage (accessed 1 June 2015).

20. National Department of Health. Tertiary and Quaternary Level Essential Medicines Recommendations. Pretoria: NDoH, 2015.

1. Council for Medical Schemes. Methodology to Assess the Cost Impact of PMB Benefit Definitions. Pretoria: CMS, 2012.

22. Chola L, Pillay Y, Barron P, Tugendhaft A, Kerber K, Hofman K. Cost and impact of scaling up interventions to save lives of mothers and children: Taking South Africa closer to MDGs 4 and 5. Glob Health Action 2015;8:27265. [http://dx.doi.org/10.3402/gha.v8.27265]

23. Chola L, McGee S, Tugendhaft A, Buchmann E, Hofman K. Scaling up family planning to reduce Chola L, McGee S, Tugendhaft A, Buchmann E, Hofman K. Scaling up family planning to reduce
maternal and child mortality: The potential costs and benefits of modern contraceptive use in South maternal and child mortality: The potential costs and benefits of modern contraceptive
Africa. PloS One 2015;10(6):e0130077. [http://dx.doi.org/10.1371/journal.pone.0130077]

24. Volmink HC, Bertram MY, Jina R, Wade AN, Hofman KJ. Applying a private sector capitation model to the management of type 2 diabetes in the South African public sector: A cost-effectiveness analysis. BMC Health Serv Res 2014;14:444. [http://dx.doi.org/10.1186/1472-6963-14-444] 